\title{
Exercise-induced airways constriction ${ }^{1}$
}

\author{
BOG.SIMONSSON ${ }^{2}$, B-E. SKOOGH, and B. EKSTRÖM-JODAL \\ The Lung Clinic, Renströmska Sjukhuset, University of Göteborg, Sweden
}

\begin{abstract}
Airway conductance was measured in a body plethysmograph at different lung volumes before and after graded exercise. In 14 out of 19 patients, mostly asthmatics, airway conductance fell significantly after exercise. These subjects also showed other signs of an increased bronchial reactivity to different stimuli, including forced breathing, hyperventilation, and cold air, but they had no exogenous allergy. The exercise-induced bronchoconstriction could be blocked by atropine in six of the nine patients tested. Exercise-induced bronchoconstriction in patients with clinical and physiological evidence of increased airway reactivity thus seems to be primarily mediated via a vagal reflex, probably from hyperresponsive airway mechanoreceptors reacting to increased ventilatory flow or lung distension. No relation was found between $\mathrm{PacO}_{2}$ or $\mathrm{pH}$ and the severity of airways constriction. Cromoglycic acid failed to block the exercise reaction in five of the six hyperreactive patients tested. In addition to or following the vagal reflex a disturbed relation between beta and alpha receptors in bronchial muscles or a release of humoral spasmogens may contribute to the progression of post-exercise airways constriction.
\end{abstract}

In normal subjects brief heavy exercise induces very slight changes in airway resistance and static compliance. Maximal inspiratory and expiratory flows are lower than those found during maximal voluntary ventilation (Granath, Horie, and Linderholm, 1959; Irnell and Swartling, 1966 ; McNeill, Nairn, Millar, and Ingram, 1966 ; Fisher, Holton, Buxton, and Nadel, 1968 ; Pierce et al., 1968 ; Gilbert and Auchinloss, 1969 ; Pierson, Bierman, and Stamm, 1969a, b).

In patients with variable airways obstruction (asthma), however, several investigations have shown an increase of expiratory flow during exercise and a post-exercise decrease in ventilatory capacity compatible with bronchial narrowing (Herxheimer, 1946 ; Nisell, 1960 ; Jones, Buston, and Wharton, 1962; Jones, Wharton and Buston, 1963; McNeill et al., 1966; Sly et al., 1968 ; Crompton, 1968 ; Irnell, Kiviloog, and Ström, 1968; Rebuck and Read, 1968 ; Fisher et al., 1968 ; Seaton, Davies, Gaziano, and Hughes, 1969 ; Pierce et al., 1968 ; Grimby and Stiksa, 1970).

The asthmatic patient shows a larger degree of airway responsiveness to a multitude of stimuli, all resulting in an increase of airways obstruction. Mechanical or chemical irritation of mechanoreceptors, probably in the bronchial mucosa,

1Presented in part at the meeting of the Thoracic Society at Keele University, England, 4-5 July, 1969

2Present address: University Lung Clinic, Lasarettet, S-221 85 Lund, Sweden causes constriction of large airways via a cholinergic vagal reflex arch (Simonsson, Jacobs, and Nadel, 1967). Irritating agents brought to the periphery of the lungs by air or blood may cause constriction of these parts of the bronchial tree. This may be due to bronchial reflexes or be caused by a release of pharmacologically active mediators acting on the smooth muscles.

Post-exercise bronchoconstriction may therefore be due to reflexes from hyperresponsive airway mechanoreceptors reacting to the increased ventilatory flow or increased tension of the lung during exercise in the same way as after forced breathing and hyperventilation (Herxheimer, 1946 ; Simonsson et al., 1967). To test this hypothesis we studied the effect of exercise on the bronchomotor tone measured as the relation between airway conductance (the reciprocal of airway resistance) and lung volume, i.e., 'conductance-lines', obtained with a volume displacement body plethysmograph.

We assessed the effect of atropine on the postexercise decrease in airway conductance and in some patients we also tested cromoglycic acid (Intal).

\section{PATIENT MATERIAL}

The patients were selected mainly on the basis of complaints of dyspnoea and wheezing occurring after exertion. Included also are two women with bron- 


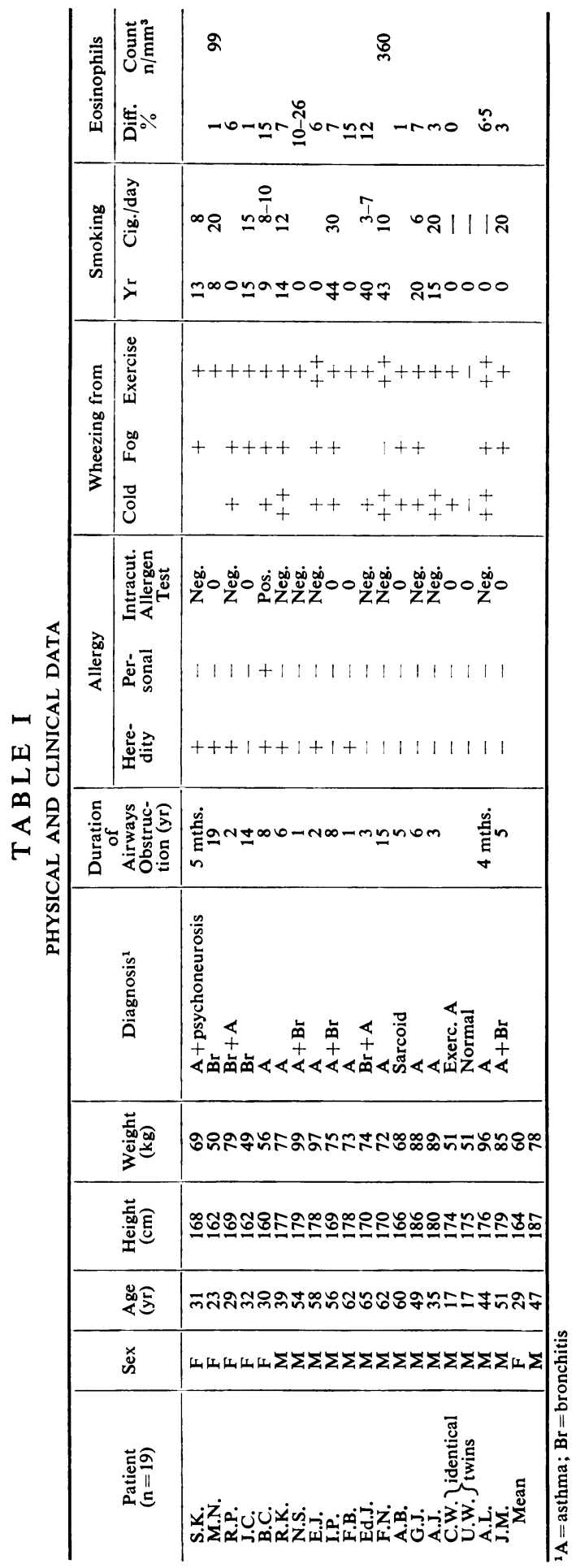


chitis, mainly due to heavy smoking, and one normal male (identical twin to one patient). We studied 14 male and 5 female patients; the mean age for the males was 47 years compared to 29 years for the female group. The physical characteristics, diagnoses, and clinical data are shown in Table I.

Intracutaneous tests with 31 allergens were negative in 10 out of 11 tested patients. One woman, B.C., had an obvious exogenous allergy to rabbit. The clinical diagnoses were asthma and/or bronchitis in 15 patients ; two had bronchitis, presumably due to smoking; A.B. had sarcoidosis verified by biopsy. U.W. was normal; we studied him because he was the identical twin to patient C.W. who had exercise-induced bronchoconstriction.

Dynamic spirometry was performed in 16 patients and was related to predicted normal values (Berglund et al., 1963). The mean vital capacity (VC) was $89 \%$ $(61-116)$, the forced expired volume in one second $\left(\mathrm{FEV}_{1}\right) \quad 78 \%(35-127)$ of that predicted, while $\mathrm{FEV}_{1} \%$ averaged $62 \%$ (54-75), the mean normal value being $76 \%(68-86)$. (Data can be obtained from the authors.)

\section{METHOD AND PROCEDURES}

All bronchodilator or other drugs with possible anticholinergic effects had been withdrawn for at least six hours before a study, mostly since the evening before. All measurements were performed in the middle of the day and, when repeated, were done at about the same time to minimize daily variations in reactivity and airways conductance. The patients were studied at rest in the sitting position in a body plethysmograph (Mead, 1960). A series of 12 measurements of airway conductance (Gaw (1/sec per cm $\mathrm{H}_{2} \mathrm{O}$ )) was performed with panting technique at different lung volumes so that six corresponded to lung volumes about half a litre above functional residual capacity (FRC) and the other six to volumes below FRC. Three of the measurements above FRC were made before and three after the six corresponding to lower lung volumes, so that we could check possible influences of time and technique on conductance. The variation of lung volumes was made in order to obtain a so-called 'conductanceline'. From this conductance-line it is possible to obtain conductance values at specific lung volumes for comparisons between consecutive conductancelines (Skoogh, to be published). These comparisons were made at different lung volumes with the thought that perhaps alterations of conductance-values at different lung volumes would reflect changes in airways of different diameters. Identical types of measurements were made after exercise or after administration of the drugs tested. The values from each of these measurements were fed into an IBM computer which was programmed to compute the "conductanceline'. From each conductance-line $\mathrm{Gaw}$ was calculated at the control total lung capacity (TLC) minus $30 \%$, $55 \%$, and $80 \%$ of VC (Fig. 3). Changes in Gaw $(\triangle \mathrm{Gaw})$ from the control conductance-line to all following lines were computed and tested at the above-mentioned lung volumes. We have mostly used the Gaw values at the volume TLC $55 \% \mathrm{VC}$, as it is closest to FRC.

\section{EXERCISE TESTS}

The exercise was performed on a bicycle ergometer (Elema, Stockholm) with the patient in the sitting position. The electrocardiogram was recorded from precordial leads with the indifferent electrode on the forehead (CH-leads). We recorded the ECG and braathing frequency immediately before and then every second minute during the work, which began with a load of $200-300 \mathrm{kpm} /$ minute. When the subject had reached steady state for breathing frequency and heart rate, usually after 4 to 6 minutes, the load was increased by steps of $200-300 \mathrm{kpm} /$ minute. After finishing the highest tolerated load the patient sat in the plethysmograph and we followed the conductance. When the recordings were stabilized, usually after 5 to 10 minutes, we measured a conductance-line for 5 minutes. In some patients we followed airway conductance for longer periods or until it had returned to control values. In order to judge a possible relation between load and effect on Gaw, some patients were stopped on submaximal loads and studied in the plethysmograph. The patients then climbed on the bicycle again and continued cycling for 6 minutes at a higher load. Conductance-values were then followed again for 10 minutes, after which we recorded another conductance-line.

Identical studies were made in nine patients before and after the administration of $1.0-1.5 \mathrm{mg}$ atropine sulphate in intravenous injection or as azrosol inhalation (particle size 0.5-5 $\mu$, Pari Optimal-nebulizer). In five patients we also tested the acute effect of the inhalation of $20 \mathrm{mg}$ cromoglycic acid 15 to 20 minutes before an exercise period; the second exercise was done in sequence with the first exercise period when the patient's Gaw had returned to control values. In some patients we repeated the tests, and some of the post-drug tests were performed on another day in order to exclude a possible decrease in bronchoconstrictor response due to repeated exercise (Davies, 1968).

In two of the patients we measured conductancelines before and after forced expirations or inspirations; in five, we also carried out studies before and after hyperventilation; in two before and after blockade with atropine and with measurements of arterial blood gases $\left(\mathrm{PaO}_{2}\right.$ and $\left.\mathrm{PaCO}_{2}\right)$. We also followed arterial blood gases simultaneously with changes in bronchial tone due to exercise. Two patients repeated the exercise test after injection of a small intravenous dose of a beta-receptor blocker, propranolol. In addition, several patients were studied regarding their bronchomotor reactions to inhaled irritants, such as citric acid or carbon dust, or after beta-receptor blockade with propranolol, followed by 
vagal block by atropine and thereafter alpha-receptor stimulation (Simonsson et al., 1970).

\section{RESULTS}

Exercise at a heavy load resulted in a statistically significant and sometimes pronounced bronchoconstriction in 14 patients. The individual results may be obtained from the authors, but the results are illustrated in Figures 1 to 9. Figure 1 shows the effect of exercise on the conductance-

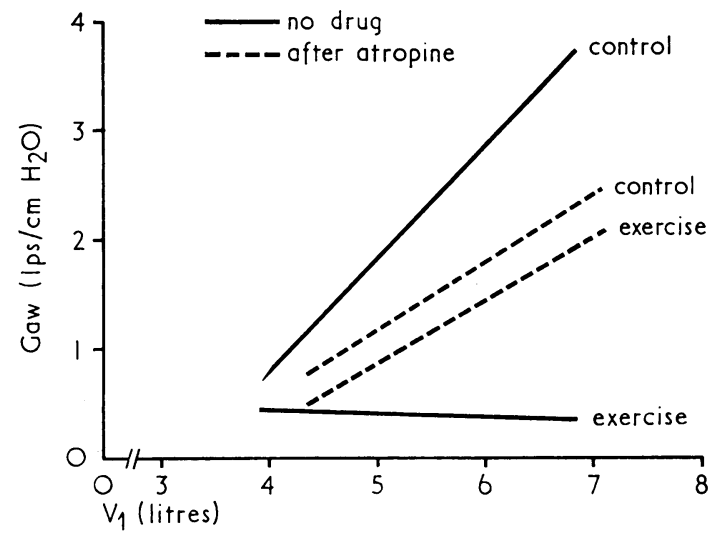

FIG. 1. Conductance-lines before and after exercise (solid lines) in male asthmatic R.K. After treatment with $1.5 \mathrm{mg}$ intravenous atropine the post-exercise bronchoconstriction was blocked (dotted lines).

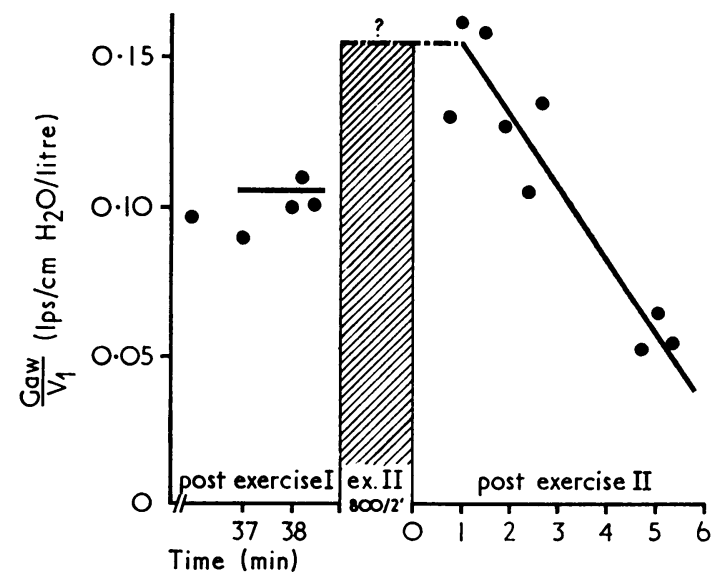

FIG. 2. Subject R.K. Specific conductance after first and second exercise periods $(800 \mathrm{kpm} / \mathrm{min}$ for 2 minutes $)$. The bronchodilatation which occurred during and immediately after the second exercise period is replaced by bronchoconstriction within 5 minutes of the end of exercise. line and blockage of the exercise effect by atropine in subject R.K. After exercise the con-듬 ductance-line was almost parallel to the volume $\overline{\bar{s}}$ axis, i.e., conductance showed very little de- $\overparen{\Phi}$ pendence on volume. The effect of further exercise in this patient is seen in Figure 2. At the peak of his post-exercise bronchoconstriction we $\overrightarrow{0}$ let the patient cycle again for 2 minutes at $800=$ $\mathrm{kpm} /$ minute ; immediately thereafter we repeated $\vec{\omega}$ measurements of Gaw and lung volumes ${ }^{1}$. The airway conductance did not return to control values for 90 minutes. The same phenomenon, $\stackrel{N}{\sim}$ an increase of Gaw, presumably occurring during iv exercise and present for 1-2 minutes after exer- $\vec{\sigma}$ cise, was seen in several patients. Figure 3 shows

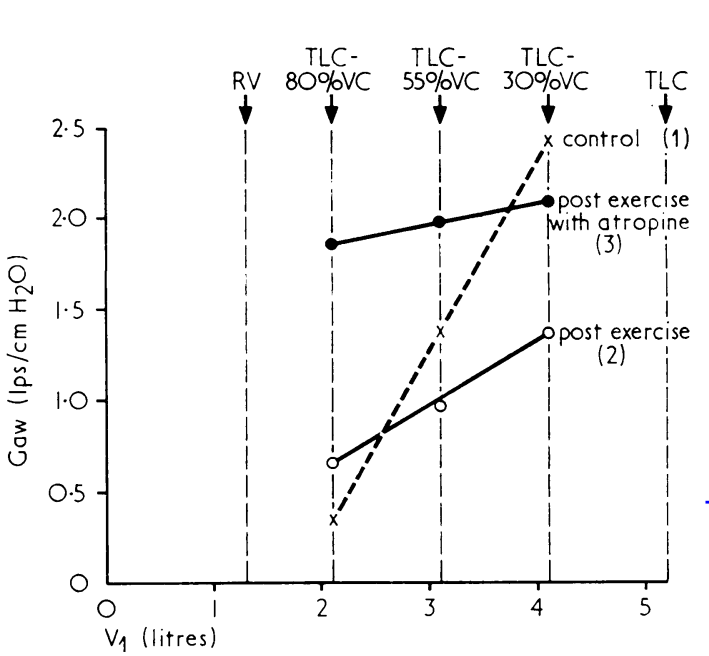

FIG. 3. Conductance-lines before and after exercise before and after atropine in subject S.K. The specifico volumes $T L C-80,-55$, and $-30 \% V C$, at which conductance values are compared to control, are marked.응

the conductance-values in the female subject S.K. at the three selected lung volumes. After exercise N Gaw decreased at the higher volumes while there was a small increase in conductance at TLC- $80 \%$ 음 of VC. After atropine and repetition of the same $\mathrm{N}$ exercise load we obtained bronchodilatation ato mid and low volumes in comparison with controke values. Figure 4 shows the effect of exercise be- $\mathbb{D}$ fore and after atropine in G.J. and the identical $\stackrel{\text { ? }}{?}$ twins C.W. and U.W. After the first exercise period there was a significant decrease in con-웅 ductance at all three specific lung volumes in G.J. and C.W. After atropine inhalation $(1-1 \cdot 3 \stackrel{\Omega}{\Omega}$

1The conductance had then increased but decreased again within 3 minutes to the same low values as after the first exercise periodo 

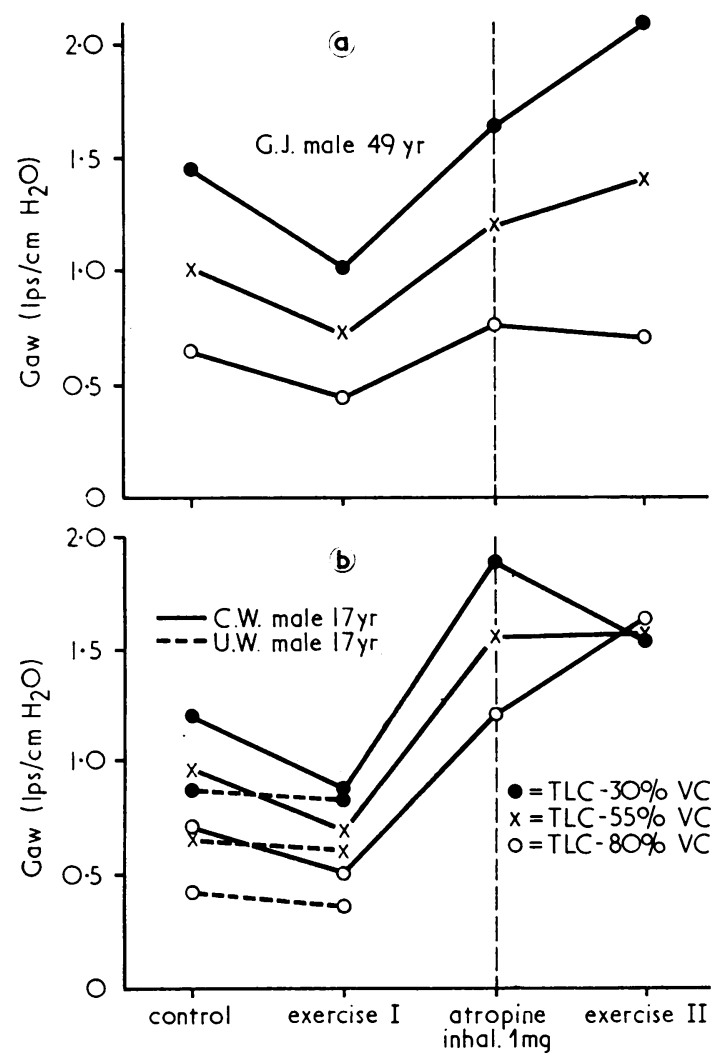

FIG. 4. Conductance at three specific control lung volumes before and after exercise before and after atropine in (a) G.J. and (b) C.W. and his twin, U.W. Post-exercise bronchoconstriction is blocked after inhalation of $1 \mathrm{mg}$ atropine sulphate.

$\mathrm{mg}$ ) bronchodilatation occurred and repetition of the same exercise load was followed by a further general increase in conductance at high and mid volumes in G.J. and especially at low volumes in C.W. This means that atropine had blocked the bronchoconstrictor response earlier elicited by this exercise load. It is of interest to note (Fig. 4b) the conductance-values and the effect of identical exercise loads obtained by U.W., the identical twin of C.W. U.W. had never experienced post-exertional dyspnoea, as had his twin brother, C.W. The 'sound' twin had somewhat lower control values, but, unlike his brother, he did not show a significant fall in conductancevalues after identical exercise.

Figure 5 summarizes the blockade obtained by atropine on the bronchoconstrictor effect of exercise in nine subjects. Without the drug all patients showed significant bronchoconstriction after

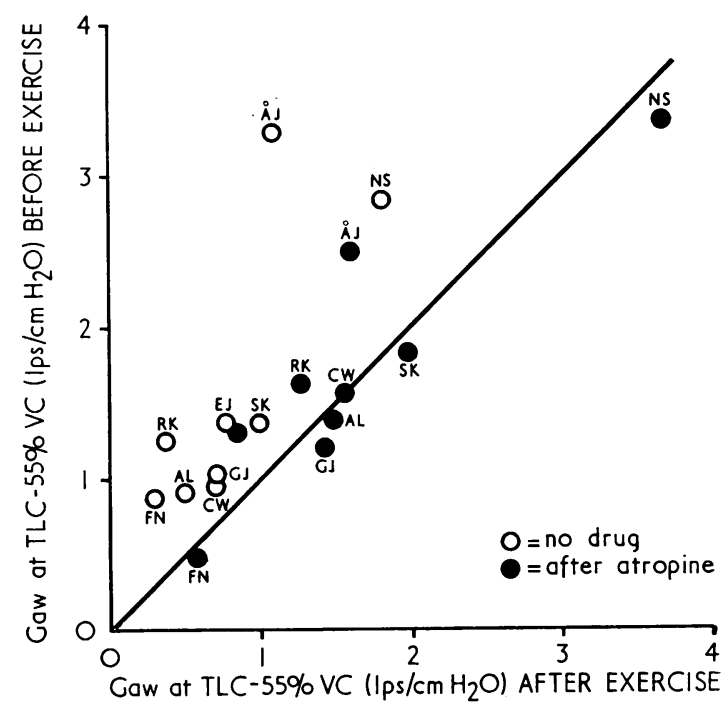

FIG. 5. Conductance at TLC 55\%VC before and after exercise before and after atropine in nine patients. All show bronchoconstriction after exercise. After exercise with atropine the conductance-values get closer to or pass the line of identity, i.e., the post-exercise bronchoconstrictor response has been diminished or blocked by atropine.

exercise. After atropine, further exercise decreased or inhibited post-exercise bronchoconstriction; five subjects even increased their airway conductance after atropine and the second exercise period compared with the control state.

The average pre-exercise airway conductance at TLC $-55 \%$ VC in nine patients was 1.45 $1 / \mathrm{sec}$ per $\mathrm{cm} \mathrm{H}_{2} \mathrm{O}$. After the first exercise period Gaw fell significantly $(\overline{\mathrm{d}}=0.79 ; t=4.76$; $P<0.005$ ). After atropine Gaw increased nonsignificantly and another period of exercise did not induce any significant decrease in Gaw $(\overline{\mathrm{d}}=$ $-0.09 ; t=0.68$ ).

Studies before and after hyperventilation with simultaneous measurements of arterial $\mathrm{CO}_{2}$ tensions were performed in seven patients; all showed bronchoconstriction after hyperventilation (Fig. 6). In subject R.K., $\mathrm{PaCO}_{2}$ decreased from 42 to $22 \mathrm{~mm}$, in subject F.N. from 45 to 30 $\mathrm{mm}$, and in subject G.J. from 43 to $22 \mathrm{mmHg}$. In three subjects, R.K., G.J., and A.L., the studies were repeated after atropine. Hyperventilation after atropine did not induce airways constriction which is in accordance with earlier studies (Simonsson et al., 1967).

Figure 7 shows the relation between arterial $\mathrm{CO}_{2}$ tensions and conductance values during various procedures in four patients. It reveals that 


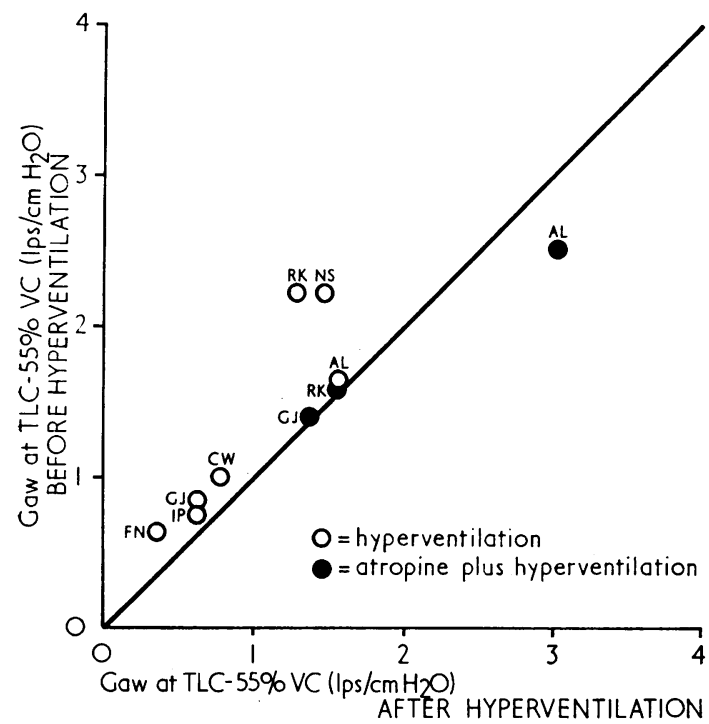

FIG. 6. Conductance before and after hyperventilation in seven patients before and in three patients after atropine. All react to hyperventilation with bronchoconstriction; this is blocked by atropine in the three tested patients.

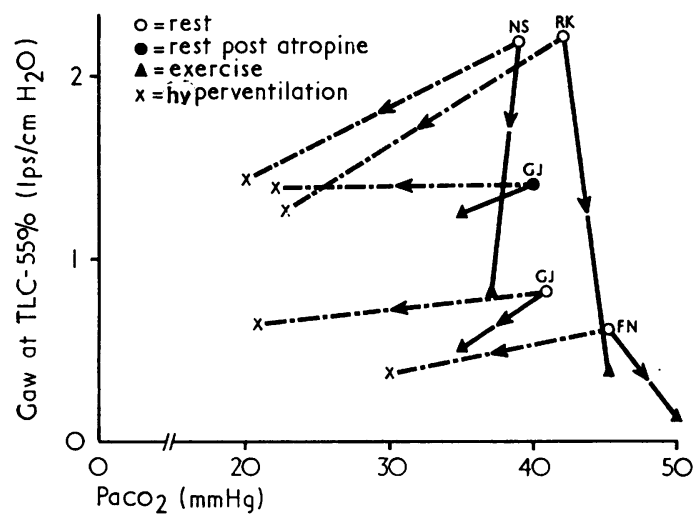

FIG. 7. Relation between conductance and arterial carbon dioxide tension at rest and after exercise and hyperventilation in four patients. No relation is found between conductance and $\mathrm{PaCO}_{2}$ values. Atropine markedly increases conductance but does not alter $\mathrm{PaCO}_{2}$.

these subjects can have the same airway conductance at the same lung volume but with different arterial $\mathrm{CO}_{2}$ tensions. For example, subject G.J. had a conductance-value of about 0.5 and $\mathrm{PaCO}_{2} 35 \mathrm{~mm}$ after exercise, and about the same conductance with a $\mathrm{PCO}_{2}$ of 22 after hyperventilation. By giving atropine to subject G.J., we were able to block the bronchoconstrictor effect of hyperventilation but still have the same $\stackrel{\vec{C}}{\circ}$ low carbon dioxide tension with a significantly흠 higher conductance-value. Thus there was no $\frac{\bar{c}}{1}$ causal relation in these patients between the level $\stackrel{\Phi}{\circ}$ of arterial $\mathrm{CO}_{2}$ tensions and airways conductance, the latter being dependent on cholinergic trans- mission as shown by the blockade by atropine. Subject F.N. even showed an increased $\mathrm{PcO}_{2}$ to $-\overrightarrow{\vec{\omega}}$ gether with a severe post-exercise bronchocon- ${ }^{\circ}$ striction.

Table II shows the arterial blood gas exchange parameters obtained in four patients before and $i v$ after exercise-induced bronchoconstriction and before and after hyperventilation. None hyper- 8 ventilated unduly during or after exercise 9 (Ferguson, Addington, and Gaensler, 1969). In subjects R.K. and F.N., severe post-exercise bron- 3

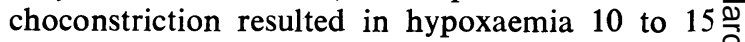
minutes after exercise. In R.K. there was no $⿱ 乛$ alveolar hypoventilation, contrary to what $\overrightarrow{0}$ happened in subject F.N. Hyperventilation in- N duced acute alkalosis and exercise promoted metabolic acidosis in F.N., who later developed hypoventilation.

Forced expirations or inspirations increase airways obstruction in certain asthmatics. We re- $\frac{\circ}{\Phi}$

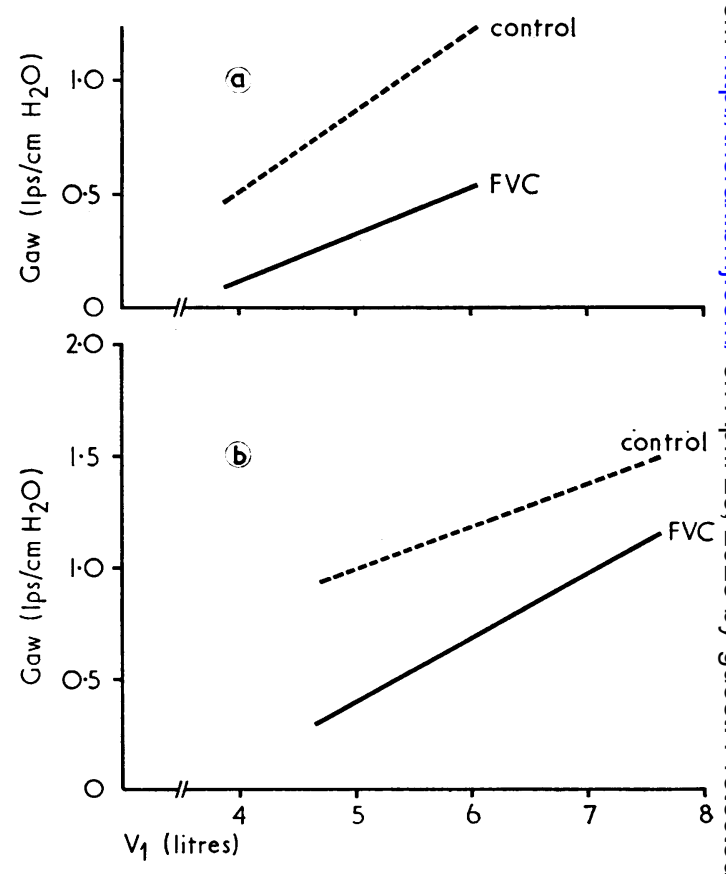

FIG. 8. Effect of forced expiration $(F V C)$ on conductancelines of (a) F.N. and (b) G.J. Bronchoconstriction occurs after forced expiration. 


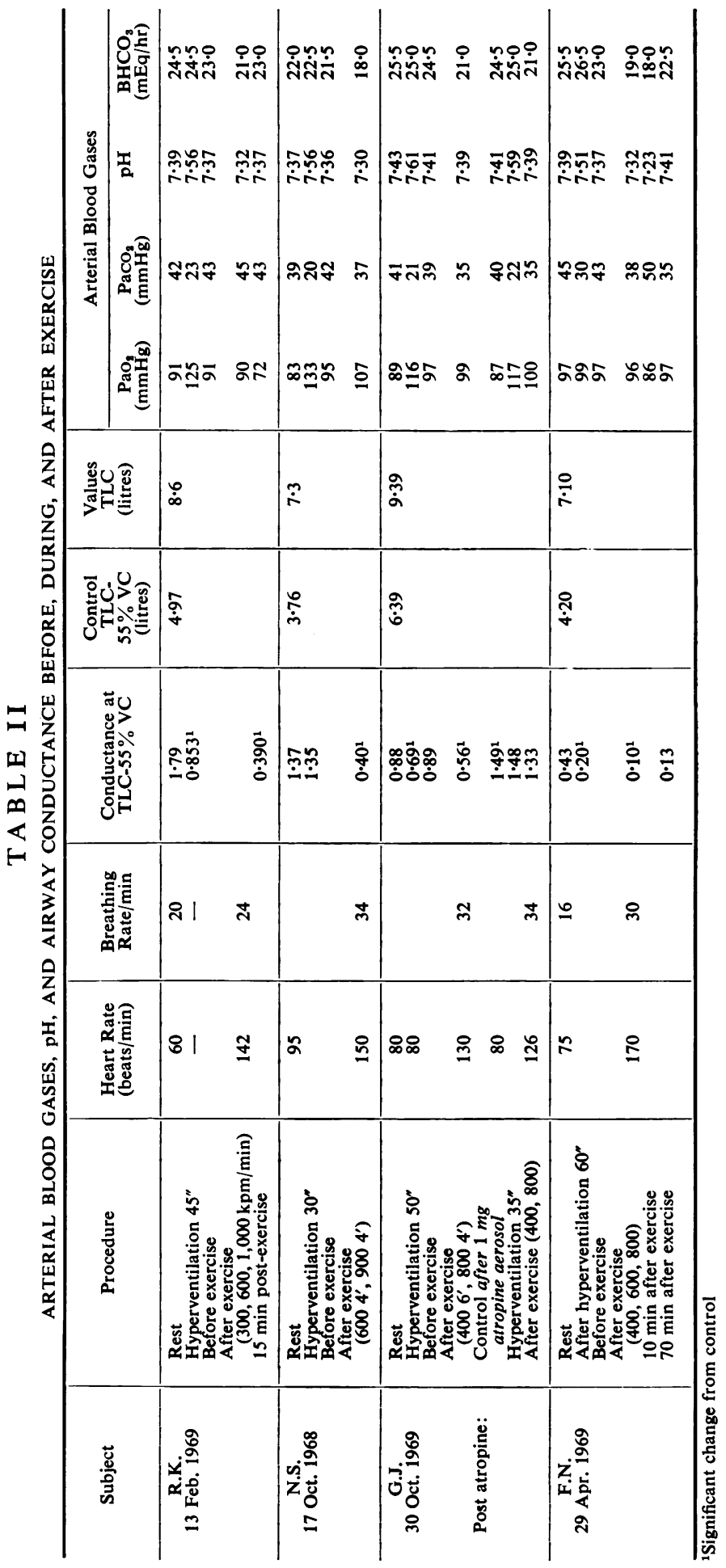


ported earlier that this response can be blocked by atropine (Simonsson et al., 1967). After repeated forced expiratory tests in subjects F.N. and G.J. there was marked bronchoconstriction (Fig. 8).

When F.N. performed exercise with increasing loads there was a further fall of Gaw after a heavier load (Fig. 9). After inhalation of atropine the bronchoconstrictor response to the same load could be inhibited.

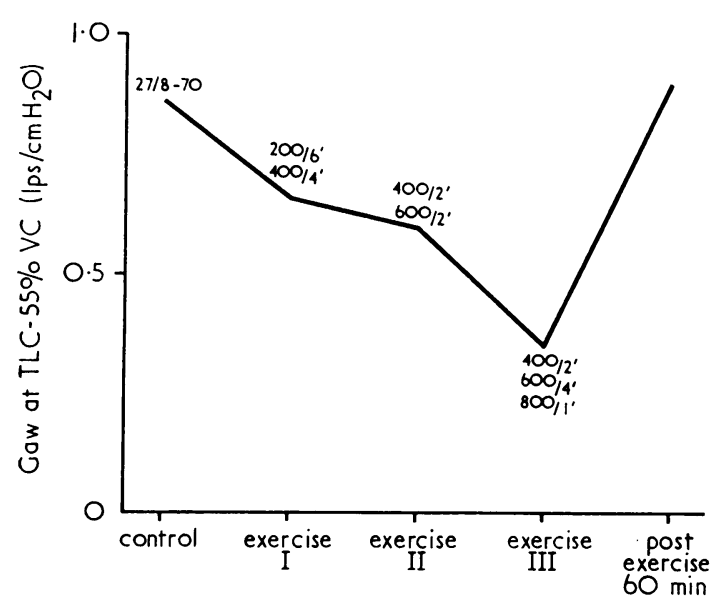

FIG. 9. Increasing workloads in repeated tests enhance the fall in conductance in subject F.N. on 27 August 1970.

In five subjects (M.N., J.C., B.C., A.B., and U.W.) we were unable to elicit significant bronchoconstriction after exercise. Two of these were young women with severe bronchitis due to heavy smoking but without signs of allergy or asthma. This suggests that asthmatics are the principal victims of post-exertional bronchoconstriction. Patient A.B. had an acute sarcoidosis in 1964 and at that time showed clear bronchoconstriction after exercise with a fall of peak expiratory flow from 220 to 150 litres/minute. Patient B.C. had an exogenous asthma with exercise-induced wheezing with upper respiratory tract infections and in cold weather.

AN ATTEMPT TO BLOCK EXERCISE-INDUCED BRONCHOCONSTRICTION WITH CROMOGLYCIC ACID Cromoglycic acid is thought to stabilize the cell membrane of mast-cells, thereby preventing the release of slow reacting substance, histamine, bradykinin or other spasmogens from an antigenantibody reaction. Several investigators have tested these substances in connexion with exer- cise-induced bronchoconstriction and have reported a partial blocking effect by pretreatment 듬 with the drug (Davies, 1968 ; Poppius et at., 1970). $\frac{\bar{\sigma}}{2}$ In three patients (S.K., F.B., G.J.) we tested the $\mathbb{\Phi}$ acute effect of the inhalation of $20 \mathrm{mg}$ cromoglycic acid 15 to 20 minutes before an exercise test.

The first exercise period induced a significant $\vec{\overrightarrow{ }}$ decrease in Gaw in all patients (Table III). There $\stackrel{\circ}{\circ}$ was no significant decrease in Gaw immediately $\overrightarrow{\overrightarrow{2}}$ after inhalation of cromoglycic acid. Measure- $x$ ment after the end of the second exercise period disclosed a significant fall in Gaw in two sub- ? jects and an increase in conductance-values in $\vec{\sigma}$ one patient. In another three patients (A.L., R.K., 을 and N.S.) with reproducible exercise-induced airways obstruction we gave cromoglycic acid be- $\bar{z}$ fore the control measurement, after which the patients performed exercise. All patients showed $\stackrel{5}{工}$ a significant fall of Gaw after exercise in spite of $\overrightarrow{0}$ pre-treatment with cromoglycic acid. Thus cromoglycic acid decreased exercise-induced airway constriction to only a small extent. The bronchoconstriction in one of the subjects who derived benefit from cromoglycic acid (G.J.) was also blocked by atropine given by inhalation or intra- $\frac{\circ}{\circ}$ venously.

After the second exercise period one to two $\overrightarrow{\overrightarrow{0}}$ inhalations of isoprenaline significantly increased 3 Gaw in four patients and intravenous atropine in two subjects so treated.

\section{DISCUSSION}

Table III shows a review of some studies on $\stackrel{\times}{-}$ exercise-induced bronchoconstriction. Sympatho-3. mimetic drugs in sufficient doses are, with one exception (Crompton, 1968), reported to decrease 3 or to block the bronchoconstrictor response after $\mathrm{O}$ exercise (Jones et al., 1962, 1963 ; Newhouse, Becklake, Macklem, and McGregor, $1964 ;$;음 McNeill et al., 1966; Rebuck and Read, 1968 ; Fisher et al., 1968 ; Allen, Cugell, Addington, and Patterson, 1971). Sympathomimetics, such as iso- $N$ proterenol exert their bronchodilator effectN through the beta-receptor system which relaxes $\sigma$ airway smooth muscle. Their action does not give information as to possible reflex mechanisms. In five studies, intravenous or subcutaneous atro- $\$$ pine has blocked the bronchoconstriction partly or completely in 12 of 28 patients tested (Jones et al., 1962 ; McNeill et al., 1966; Sly et al., $\mathbb{\mathbb { Q }}$ 1968 ; Crompton, 1968 ; Stanescu and Teculescu, 1970).

Forced expirations or inspirations increase air 2 way obstruction in asthmatics (Herxheimer, $1946 ;$ 


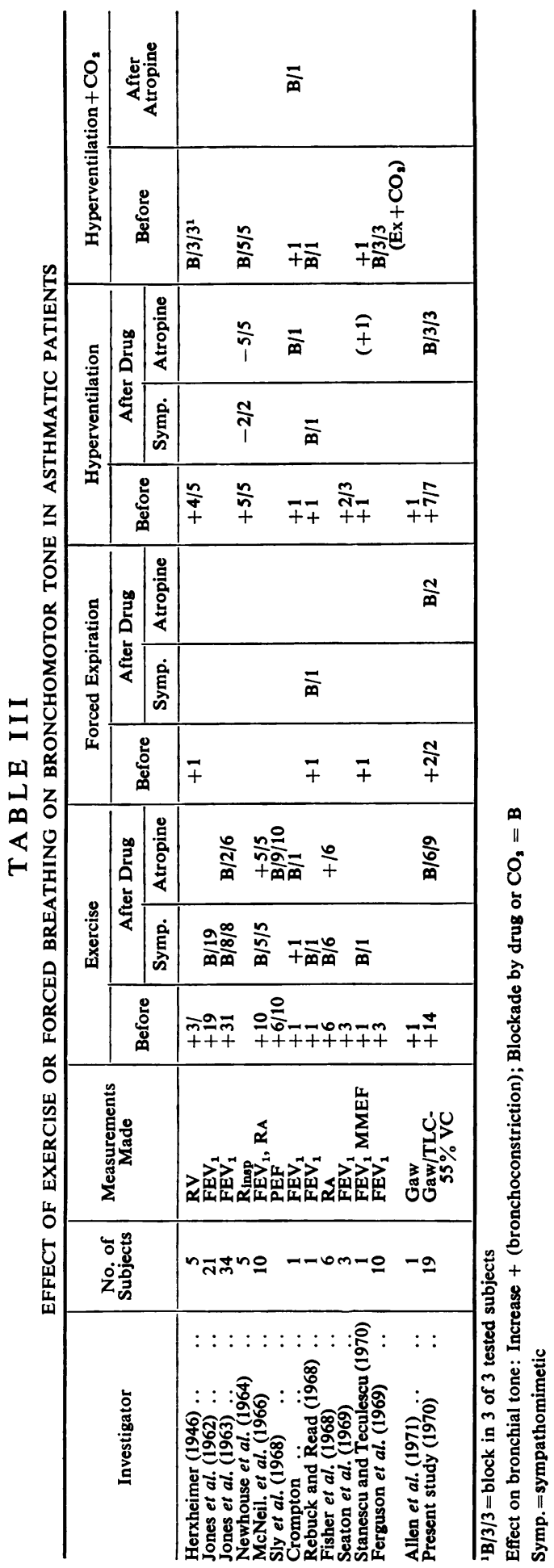


Rebuck and Read, 1968 ; Stanescu and Teculescu, 1970); we found that this response can be blocked by atropine (Simonsson et al., 1967). Hyperventilation was suspected by Herxheimer (1946) to be the cause of post-exertional asthma. $\mathrm{He}$ believed that the lowering of arterial carbon dioxide tension caused the bronchoconstriction and subsequently reported no bronchial constriction in three patients after hyperventilation with $\mathrm{CO}_{2}$ mixtures. Bronchodilatation following $\mathrm{CO}_{2}$ breathing has been reported in another 18 patients (McNeill et al., 1966 ; Newhouse et al., 1964 ; Rebuck and Read, 1968 ; Fisher et al., 1968 ; Ferguson et al., 1969). Crompton (1968) and Stanescu and Teculescu (1970) found that $\mathrm{CO}_{2}$ did not prevent exercise-induced bronchoconstriction although Crompton found that atropine prevented it. Nissell (1960) reported a $16 \%$ increase in airway resistance during exercise and hyperventilation in seven patients with different kinds of lung diseases.

Hypocapnia in normal subjects induces airway constriction. The bronchoconstrictor action of low $\mathrm{PCO}_{2}$ down to $15 \mathrm{mmHg}$ is mediated via vagal paths and can be blocked by atropine (Sterling, 1968). In patients with sensitized mechanoreceptors, hyperventilation would then be a strong stimulation to bronchoconstriction. The addition of carbon dioxide, on the other hand, acts locally, relaxing smooth airway muscle (Samanek and Aviado, 1967). The local bronchodilating effect of $\mathrm{CO}_{2}$ mixtures is most likely non-specific (Newhouse et al., 1964 ; Sterling, 1968). Consequently, when $\mathrm{CO}_{2}$ is withdrawn in tests on exertional bronchoconstriction the obstruction has been shown to return (Fisher et al., 1968).

None of our subjects showed signs of hyperventilation during work or a $\mathrm{PaCO}_{2}$ below 35 $\mathrm{mmHg}$ at the end of an exercise period which resulted in airways constriction, neither was there marked metabolic acidosis (Table II). Hypocapnia after hyperventilation (Fig. 6) also induced bronchoconstriction, as did a single forced expiration (Fig. 8a, b).

The $\mathrm{PCO}_{2}$ in the lung strongly influences the mechanism which regulates the bronchomotor tone; perhaps hypocapnia increases the sensitivity of vagal nerve endings or smooth airway muscles to irritating stimuli, i.e., by calcium ion changes? There seems to be no reason, however, to believe that hypocapnia is the main trigger to exercise-induced bronchoconstriction.

During exercise a decrease in airway muscular tone seems to occur, as evidenced by recordings of increased airflows during work (Pierce et al., 1968 ; Irnell et al., 1968 ; Lefcoe, 1969 ; Jonsson, 음 1971). Our findings of an increase in Gaw im- क mediately after repeated exercise following work- $\mathbb{\nabla}$ induced airways constriction argue in the same direction. Jones' report that isoproterenol abolished not only the bronchoconstriction after exercise but also the ventilatory increase (as a $\vec{F}$ result of reflex bronchodilatation?) during and $\sigma^{\omega}$ immediately after exercise makes these changes $\overrightarrow{\vec{x}}$ likely to be reflex variations in bronchial tone i mediated via sympathetic nerves or catecholamines (Jones et al., 1962). Similarly, sympathetic nerves mediate an increase in nasal patency 8 during exercise (Richerson and Seebohm, 1968).

The well-known increase in bronchial reactivity to various agents acting over vagal paths in patients with asthma can explain a disturbed balance between sympathetic bronchodilating activity and parasympathetic bronchozonstrictor $\overrightarrow{0}$ activity during and after exercise. When the sym- N pathetic activity diminishes after exercise an increased parasympathetic drive remains from sensitized mechanoreceptors and perhaps from bronchial smooth muscles causing bronchial constriction.

There is a connexion between post-exercise bronchoconstriction in the present study and a concomitant general increase in airway responsiveness to cold air, forced expirations or hyperventilation, indicating participation of a reflex mechanism, as suggested. A tendency in several $\bar{\partial}$ subjects towards lowering of responsiveness to exercise with time, improvement of climate or cessation of smoking simultaneously with a de- $\underline{3}$ cline of respiratory symptoms also favours this theory. The primary bronchoconstriction thus seems to be due to bronchial vagal reflexes in 응 these patients, as it can be blocked by inhaled atropine. The finding that once post-exercise bronchoconstriction has occurred it is difficult to release, was confirmed in two patients. In both, $\sigma$ the bronchoconstriction could be prevented by $N$ atropine. This suggests that when stimuli via the N vagal reflex have induced bronchospasm, other mechanisms may add to airways obstruction. Thus, there may be a further cause of exercise- $\frac{\mathrm{C}}{0}$ induced bronchoconstriction, such as a release of $\stackrel{\mathbb{P}}{\rightarrow}$ mediators acting directly on smooth airway 0 muscles, and therefore not completely blockable $\stackrel{\circ}{\circ}$ by atropine, especially once the vagal reflex has $\mathbb{D}$ initiated bronchoconstriction.

Recent studies on the excretion of histamine $\frac{0}{2}$ before and after exercise have failed to show a post-exercise increase in the hyperreactive type of 
patient (Granerus, Simonsson, Skoogh, and Wetterquist, 1971). Bradykinin has been mentioned as a possible cause of bronchoconstriction (McNeill et al., 1966 ; Seaton et al., 1969). In the majority of patients with airways obstruction bradykinin seems to act mainly on the vagal reflex (Simonsson, Skoogh and Svedmyr, to be published). The protective effect of aspirin in some patients with asthma also suggests SRS-A, SRS-C or prostaglandin as possible mediators of bronchoconstriction.

In some individuals intravenous atropine blocked the bronchoconstrictor response to exercise ; in others, this method seemed less efficient while atropine-aerosol blocked the post-exercise response. The possible difference in effect between the intravenous and the inhalation routes may be due to a higher atropine concentration or the higher affinity to atropine in the lung after inhalation. This would also suggest perhaps that part of the bronchoconstrictor response is a peripheral bronchobronchial cholinergic reflex besides the central vagal reflex, which would be more affected by parenterally active atropine.

A more complicated but possible mechanism for post-exercise bronchoconstriction would depend on a partial beta-receptor blockade or sympathetic inhibition. During the post-exercise period with decreasing sympathetic tone this would cause a much lower beta-stimulation parallel to an increased flow of parasympathetic impulses from sensitized airway receptors. The occurrence of a nasal drip after exercise in at least two of our patients can be explained by parasympathetic stimulation of the nasal mucosae (Malcomson, 1959). Zaid, Beall, and Heimlich (1968) failed to show any bronchoconstriction in six normal patients after beta-blockade. We have not been able to produce any evidence of a partial betablockade in patients with early asthma; dose response relations for isoproterenol infusions and in vitro tests on bronchial muscle seem to show a normal response (Svedmyr, Simonsson, and Skoogh, to be published). In two patients, we failed at one time to elicit a significant fall in Gaw after exercise, but we could provoke this by the injection of only $0.5 \mathrm{mg}$ propranolol and repetition of exercise. The most likely reason is that propranolol decreased the bronchodilating effect of sympathetic activity, thereby accentuating the parasympathetic vagal bronchoconstrictor tone. The beta-blockade was not very marked, as we could easily obtain a good bronchorelaxation after exercise by normal doses of isoproterenol (N.S.) or salbutamol (F.B.). The beta-receptor blockade may have been suffici- ent, however, to remove the bronchoconstrictor effect of alpha-receptor stimulation by released epinephrine or catecholamines. In subjects R.K. and N.S., we consequently could elicit a significant bronchoconstriction by alpha-stimulation (phenylephrine) after intravenous atropine and propranolol (Simonsson et al., 1970).

The weak blocking effect from cromoglycic acid is not likely to be due to insufficient dosage; even in studies with prolonged treatment the protection has been only partial (Poppius et al., 1970). As we have no evidence of an acute release of histamine or SRS-A from ruptured mast-cells during exercise, the partial blocking effect by cromoglycic acid may be due to activity against SRS-A or prostaglandin or to a pharmacological effect, for example, an alpha-blocking property. These theories are now being investigated.

\section{CONCLUSIONS}

A certain number of asthmatic patients develop increased airways obstruction after termination of exercise. Bronchoconstriction in patients with clinical and physiological evidence of increased airway reactivity seems to be due primarily to a vagal reflex, probably mediated via hyper-responsive airway mechanoreceptors reacting to increased ventilatory flow or lung distension. The effect is probably increased by a sympathetic tone which lowers airway resistance during exercise but which declines after termination of exercise, resulting in a relative preponderance of parasympathetic bronchoconstrictive tone. After reflex initiation via the vagal reflex it is possible for humoral substances to be released, acting to increase the bronchoconstriction. This may occur especially in a more allergic type of subject.

No relation was found between the $\mathrm{PaCO}_{2}$ or $\mathrm{pH}$ and the severity of exercise-induced airways obstruction. Atropine showed a significant blocking effect on post-exercise bronchoconstriction in the hyperreactive type of patient while cromoglycic acid was ineffective in most cases. Another possible cause for post-exertional bronchoconstriction could be a partial beta-blockade and an alphareceptor stimulation.

\section{REFERENCES}

Allen, T. W., Cugell, D. W., Addington, W. W., and Patterson, R. (1971). Postexercise bronchospasm. Chest, 59, 557. 
Berglund, E., Birath, G., Bjure, J., Grimby, G., Kjellmer, I., Sandqvist, L., and Söderholm, B. (1963). Spirometric studies in normal subjects. I. Forced expirograms in subjects between 7 and 70 years of age. Acta med. scand., 173,185 .

Crompton, G. K. (1968). An unusual examples of exerciseinduced asthma. Thorax, 23, 164.

Davies, S. E. (1968). Effect of disodium cromoglycate on exercise-induced asthma. Brit. med. J., 3, 593.

Ferguson, A., Addington, W. W., and Gaensler, E. A. (1969). Dyspnoea and bronchospasm from inappropriate post exercise hyperventilation. Ann. intern. Med., 71, 1063.

Fisher, H. K., Holton, P., Buxton, R. St. J., and Nadel, J. A. (1968). Mechanism of exercise-induced bronchoconstriction in asthma (Abstract). Clin. Res., 16, 162.

Gilbert, R., and Auchincloss, J. H., Jr. (1969). Mechanics of breathing in normal subjects during brief severe exercise. J . Lab. clin. Med., 73, 439.

Granath, A., Horie, E., and Linderholm, H. (1959). Compliance and resistance of the lungs in the sitting and supine positions at rest and during work. Scand. J. clin. Lab. Invest., 11, 226.

Granerus, G., Simonsson, B. G., Skoogh, B. E., and Wetterqvist, H. (1971). Exercise-induced bronchoconstriction and histamine release. Scand. J. resp. Dis (in press).

Grimby, G., and Stiksa, J. (1970). Flow-volume curves and breathing patterns during exercise in patients with obstructive lung disease. Scand. J. clin. Lab. Invest., 25, 303.

Herxheimer, H. (1946). Hyperventilation asthma. Lancet, $1,83$.

Irnell, L., Kiviloog, J., and Ström, G. (1968). Variation of maximal expiratory flow at exercise test in patients with bronchial asthma. Bronches, 18, 506.

_- and Swartling, S. (1966). Maximal expiratory flow at rest and during muscular work in patients with bronchial asthma. Scand. J. resp. Dis., 47, 103.

Jones, R. S., Buston, M. H., and Wharton, M. J. (1962). The effect of exercise on ventilatory function in the child with asthma. Brit. J. Dis. Chest, 56, 78.

- Wharton, M. J., and Buston, M. H. (1963). The place of physical exercise and bronchodilator drugs in the assessment of the asthmatic child. Arch. Dis. Childh., 38, 539.

Jonsson, B. (1971). Personal communication.

Lefcoe, N. M. (1969). The time course of maximum ventilatory performance during and after moderately heavy exercise. Clin. Sci., 36, 47.

Malcomson, K. G. (1959). The vasomotor activities of the nasal mucous membrane. J. Laryng., 73, 73.

McNeill, R. S., Nairn, J. R., Millar, J. S., and Ingram, C. G. (1966). Exercise-induced asthma. Quart. J. Med., 35, 55.
Mead, J. (1960). Volume displacement body plethysmographб for respiratory measurements in human subjects. J. appl. Physiol., 15, 736.

Newhouse, M. T., Becklake, Margaret R., Macklem, P. T., and McGregor, M. (1964). Effect of alterations in end- $\varrho$ tidal $\mathrm{CO}_{2}$-tension on flow resistance. J. appl. Physiol., 19, 745.

Nisell, O. I. (1960). Mechanical properties of the lungs during. exercise in patients with cardiac or pulmonary disease. $\overrightarrow{\mid}$ Acta med. scand., 166, 107.

Pierce, A. K., Luterman, D., Loudermilk, J., Blomqvist, G., and Johnson, R. L., Jr. (1968). Exercise ventilatory patterns in normal subjects and patients with airway obstruction. J. appl. Physiol. 25, 249.

Pierson, W. E., Bierman, C. W., and Stamm, S. J. (1969a). iN Cycloergometer-induced bronchospasm. J. Allergy, 43, 136. $-(1969 \mathrm{~b})$. Factors influencing exercise-induced bronchospasm in children (Abstract). J. Allergy, 41, 93.

Poppius, H., Muittari, A., Kreus, K. -E., Korhonen, O., and Viljanen, A. (1970). Exercise asthma and disodium $\overline{\widehat{\Omega}}$ cromoglycate. Brit. med. J., 4, 337.

Rebuck, A. S., and Read, J. (1968). Exercise-induced asthma. $\overrightarrow{0}$ Lancet, 2, 429.

Richerson, H. B., and Seebohm, P. M. (1968). Nasal airway response to exercise. J. Allergy, 41, 269.

Samanek, M., and Aviado, D. M. (1967). Interrelationships between pulmonary blood flow and bronchomotor tone: $\mathrm{Po}_{2}$ and $\mathrm{PCO}_{2}$. J. appl. Physiol., 22, 719.

Seaton, A., Davies, G., Gaziano, P., and Hughes, R. O.® (1969). Exercise-induced asthma. Brit. med. J., 3, 556.

Simonsson, B. G., Andersson, R., Bergh, N. P., Skoogh, 음 B. E., and Svedmyr, N. (1970). In vivo and in vitro studies of pharmacological effects on different receptors? regulating bronchial tone in man. Chronic Bronchitis III, International Symposium, Groningen. Ed. Royal von Gorcum, Assen, Netherlands.

- Jacobs, F. M., and Nadel, J. A. (1967). Role of autonomic nervous system and the cough reflex in the. increased responsiveness of airways in patients with obstructive airway disease. J. clin. Invest., 46, 1812.

Skoogh, B. E. (To be published).

Sly, R. M., Heimlich, E. M., Ginsburg, J., Busser, R. J., and₹ Strick, L. (1968). Exercise-induced bronchospasm:o evaluation of metaproterenol. Ann. Allergy, 26, 253.

Stanescu, D. C., and Teculescu, D. B. (1970). Exercise- and cough-induced asthma. Respiration, 27, 377.

Sterling, G. M. (1968). The mechanism of bronchocon-N striction due to hypocapnia in man. Clin. Sci., 34, 277.

Zaid, G., Beall, G. N., and Heimlich, E. M. (1968). Bronchial response to exercise following beta-adrenergic blockade J. Allergy, 42, 177. 